\title{
Oxygen at birth and prolonged cerebral vasoconstriction in preterm infants
}

\author{
K E Lundstrøm, O Pryds, G Greisen
}

\begin{abstract}
To determine if the use of oxygen in the delivery room influences subsequent global cerebral blood flow (CBF), 70 infants of gestational age of less than 33 completed weeks were randomly assigned to receive room air (group I) or $80 \%$ oxygen (group II) during the initial stabilisation at birth. In group I supplemental oxygen was administered on clinical indications, when required. After being admitted to the neonatal intensive care unit all infants were treated according to our normal practice. At a postnatal age of 2 hours CBF was measured by xenon clearance. Seventy four per cent of the infants in group $I$ were successfully stabilised without the need for supplemental oxygen. CBF was significantly higher in group I than in group II (CBF median (interquartile range): 15.9 $(13.6-21.9) \quad v \quad 12.2 \quad(10 \cdot 7-13.8) \quad \mathrm{ml} / 100$ $\mathrm{g} /$ minute). Differences in oxygen exposure seemed to be the only explanation for the differences in CBF. No differences in short term outcome were found between the groups.
\end{abstract}

(Arch Dis Child 1995; 73: F81-F86)

Keywords: cerebral blood flow, preterm, resuscitation.

Inhalation of $100 \%$ oxygen reduces global cerebral blood flow (CBF) in newborn infants. ${ }^{12}$ However, the duration of vasoconstriction following hyperoxaemia in the neonatal period remains unclear. The sensitivity to hyperoxaemia seems to decrease with maturity, and the effect may be prolonged in the immature brain. ${ }^{3}$ In newborn kittens the large arteries of the retina were severely constricted for several minutes by exposure to $80 \%$ oxygen. 4 At normalisation of $\mathrm{Po}_{2}$, a similarly long lasting decrease in CBF velocity induced by a threefold increase in $\mathrm{PO}_{2}$ was demonstrated in preterm infants; $\mathrm{CBF}$ velocity normalised along with $\mathrm{PO}_{2}$ in term infants. ${ }^{5}$

Extremely low birthweight infants can be

Department of Neonatology, The National University Hospital

Rigshospitalet,

Copenhagen, Denmark

$\mathrm{K}$ E Lundstrøm

O Pryds

G Greisen

Correspondence to:

Dr K E Lundstrom,

Department of Neonatology,

The National University

Hospital Rigshospitalet,

Blegdamsvej 9, DK-2100

Cph O, Denmark.

Accepted 30 April 1995 treated appropriately with room air or $30-40 \%$ oxygen in the delivery room. ${ }^{6}$ Routine use of $80-100 \%$ oxygen during the initial stabilisation at birth, as often recommended, ${ }^{7}$ may therefore produce hyperoxaemia in some infants. Greisen ${ }^{8}$ and Pryds et $a l^{9}$ showed that CBF in newborn preterm infants is low compared with these values in older children and adults. These results have recently been confirmed by other authors. ${ }^{10}$ The infants described by Greisen and Pryds were treated with $100 \%$ oxygen at birth. We therefore hypothesised that low CBF values might be caused by an extremely prolonged cerebral vasoconstriction following a few minutes of hyperoxaemia caused by routine use of oxygen shortly after birth. To test this, we conducted a randomised, controlled trial in which premature infants were assigned to receive room air or $80 \%$ oxygen during the initial stabilisation in the delivery room. Two hours after birth we measured CBF, and in an attempt to test for any systemic effect of hyperoxaemia, we also tested cardiac left ventricular output (LVO), mean arterial blood pressure (MABP), and heart rate at the same time.

\section{Method}

Enrolment criteria were a gestational age of $<33$ completed weeks and no known severe malformations. Women with incipient preterm delivery (gestational age of $<33$ weeks) were informed about the study and random allocation was delayed until immediately before delivery. Patients were not pre-selected, but enrolment in the study was undertaken only with one of the authors present. Infants were randomly assigned to receive initially room air (group I) or $80 \%$ oxygen (group II) during stabilisation in the delivery room. A subgroup of 12 infants in each group were monitored by pulse oximetry in the delivery room to test the differences in oxygenation during the treatment. This kind of monitoring is not routine in the department and could not be performed on all infants as no pulse oximeter was continuously available. Ten healthy, term infants not receiving any treatment were monitored by pulse oximetry during the first 10 minutes after birth for comparison with the preterm infants. Infants were excluded before randomisation if severe malformations or hydrops had been diagnosed antenatally. Exclusion criteria after delivery were severe congenital malformations, or need for mechanical ventilation, or death before 2 hours of age. Mechanical ventilation was used as an exclusion criterion because it has a major impact on both systemic and cerebral haemodynamics.

Data on all inborn premature infants from 1 
capacity. The pressures used for this ventilation depended on the clinical evaluation of the response. No pressure monitoring was performed. After the initial manoeuvres treatment was continued with continuous positive airway pressure (CPAP) or ventilation by face mask. The patient was endotracheally intubated only if it proved impossible to establish sufficient respiration by face mask. The need for intubation was evaluated clinically. No monitoring of blood gases or collection of blood samples was routinely performed in the delivery room.

If the heart rate failed to normalise within the first minute of stabilisation in infants receiving room air, $30-40 \%$ of oxygen was administered for one minute and during the next minutes the fraction of inspired oxygen $\left(\mathrm{FIO}_{2}\right)$ was increased in steps of $10 \%$ until an acceptable response was achieved. Once heart rate and spontaneous respiration were stable, the infant was moved to the neonatal intensive care unit.

Oxygen saturation was monitored with pulse oximetry (OXI Radiometer, Copenhagen) and recorded in the delivery room in 12 patients in each randomisation group, and in 10 healthy term infants not receiving any treatment after birth. Monitoring by pulse oximetry was limited by availability. The probe was placed on the right hand. As this monitoring is not routine in our department the person treating the infant was not allowed to see the pulse oximeter readings. The person reading the recordings was unaware of the patient data.

In intensive care all infants were treated according to the clinical signs. CPAP was started shortly after admission, as was continuous transcutaneous monitoring of $\mathrm{Po}_{2}\left(\mathrm{TcPo}_{2}\right)$ and $\mathrm{PCO}_{2}\left(\mathrm{TcPCO}_{2}\right)$ (TINA, Radiometer, Copenhagen) and electrocardiography (ECG). Until transcutaneous measurements were reliable, typically at an age of 20 to 30 minutes, oxygen was administered according to clinical judgment; $21-30 \%$ oxygen was often given initially. $\mathrm{TcPO}_{2}$ was kept in the range of 7-11 $\mathrm{kPa}$, if possible. Infusion of $10 \%$ glucose and an intravenous bolus of aminophylline or caffeine citrate were routinely administered, and vitamins $\mathrm{E}$ and $\mathrm{K}$ were administered by intramuscular injection. The indications for intubation and mechanical ventilation were $\mathrm{FIO}_{2}$ of $>0.60, \mathrm{PCO}_{2}$ of $>9.5 \mathrm{kPa}$, and $\mathrm{pH}$ $<7 \cdot 25$ or recurrent apnoea. Using nasal CPAP and these strict guidelines for intubation, it is possible to maintain most preterm infants spontaneously breathing during the first days of life. ${ }^{11}$

Two hours after birth a capillary blood sample was collected for analysis of blood glucose and haemoglobin concentration, $\mathrm{PCO}_{2}$, and $\mathrm{pH}$. MABP was measured oscillometrically (Dinamap, Criticon, Tampa, USA), and heart rate and transcutaneous values were recorded as well as the actual ventilatory support. The oxygen status was evaluated by $\mathrm{TcPo}_{2}$. $\mathrm{CBF}$ and LVO were also measured at the same time.

All CBF measurements were performed with the infant undisturbed in the incubator, as described before. ${ }^{12}$ One half to $1 \mathrm{mCi} / \mathrm{kg}$ xenon in $0.9 \%$ saline (total volume $1 \mathrm{ml}$ ) was injected into a peripheral vein over 10-15 seconds. The clearance was recorded by scintillation detectors placed over one frontoparietal region and the thorax, respectively. $\mathrm{CBF}$ was calculated from the time the activity of xenon in the lung had decreased to $15 \%$ of its peak activity, using the Obrist compartment analysis, modified to adjust for increased recirculation of tracer. $\mathrm{CBF}_{\infty}$ is the weighted mean of grey and white matter flow. The blood-brain barrier coefficient was set to $0.8 \mathrm{ml} / \mathrm{g}$ and adjusted for blood $\mathrm{Hb} .^{13}$ As the neonatal head is small and the scintillation geometry allows for counting from a volume of $100-200 \mathrm{ml}$, $\mathrm{CBF}_{\infty}$ is considered to represent global CBF and is expressed as $\mathrm{ml} / 100 \mathrm{~g} /$ minute. The testretest variation of the method is $10-15 \% .^{14}$ Patient radiation was $0.2 \mathrm{mSv}$. Analyses of xenon data were performed without knowledge of randomisation.

Measurement of the internal diameter (D) of the ascending aorta (trailing edge to leading edge) just above the aortic valve was performed in late systole using combined B- and M-mode echocardiography from a parasternal short axis view (Aloka SSD 800 with a $5 \mathrm{mHz}$ probe). The space and time average mean velocity (V) was measured at the same site using pulsed Doppler ultrasound velocimetry with a specially designed $5 \mathrm{mHz}$ probe positioned at the suprasternal notch (Alfred Vingmed). LVO is derived by the formula:

$$
\mathrm{LVO}=\frac{\frac{\pi \times \mathrm{D}^{2}}{4} \times \mathrm{V} \times 60}{\text { Birthweight }} \mathrm{ml} / \mathrm{kg} / \text { minute }
$$

This method correlates well with cardiac output measured with thermodilution in infants. ${ }^{1516}$

\section{DATA ANALYSIS}

A power test with $\alpha=0.05$ and $\beta=0.10$ revealed that $35+35$ patients were required to detect a $10 \%$ difference in CBF between the groups.

To adjust for positive skewing, $\mathrm{CBF}$ values were transformed logarithmically to obtain homogeneity of variance in the analyses.

Statistical analyses were done using the Mann-Whitney $U$ test for unpaired data and the $\chi^{2}$ test for categorical data. Stepwise linear regression analysis was used to determine whether the effect of randomisation on CBF could be indirect through differences in other variables.

The computer program SPSSpc+ (Chicago, USA) was used for statistical evaluation. Parental consent was obtained for all infants before randomisation. The protocol was approved by the research ethics committee for the counties of Copenhagen and Frederiksberg. The study was carried out in the period 1 November 1990 to 15 April 1993.

\section{Results}

Mean $\mathrm{SaO}_{2}$ increased in the 12 infants in each of the randomisation groups during stabilisation as well as in the healthy term infants 


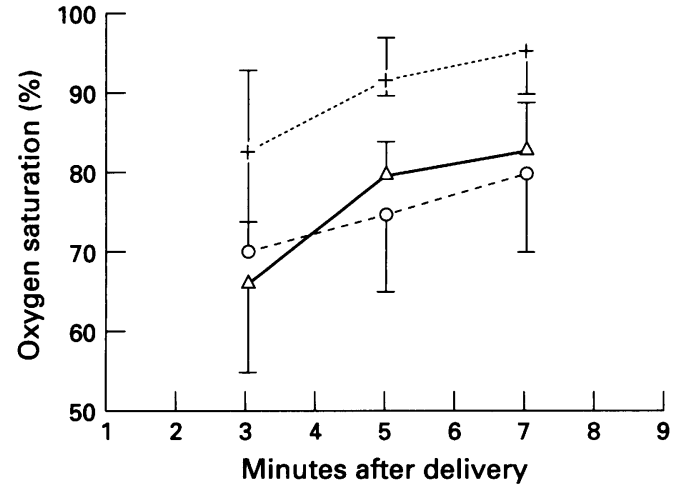

Figure 1 Median, upper, and lower quartile values of pulse oximetry readings in group I (O, $21 \%$ oxygen), group II (,$+ 80 \%$ oxygen) and in 10 healthy term infants $(\Delta$, normal). For exact values and $P$ values of differences, see table 1.

Table 1 Data of pulse oximetry readings (\% oxygen saturation) in 12 infants treated with $21 \%$ oxygen at birth (group I), 12 treated with $80 \%$ oxygen at birth (group II), and 10 normal term infants (term, no treatment)

\begin{tabular}{lllll}
\hline $\begin{array}{l}\text { Time after } \\
\text { birth }\end{array}$ & $\begin{array}{l}\text { Term, no treatment } \\
(n=10)\end{array}$ & $\begin{array}{l}\text { Group I } \\
(n=12)\end{array}$ & $\begin{array}{l}\text { Group II } \\
(n=12)\end{array}$ & $\begin{array}{l}P \\
\text { value }\end{array}$ \\
\hline 3 Minutes & $66(56-75) \%$ & $70(65-74) \%$ & $83(74-93) \%$ & 0.009 \\
5 Minutes & $80(55-85) \%$ & $75(65-87) \%$ & $92(90-97) \%$ & 0.0001 \\
7 Minutes & $83(68-88) \%$ & $80(70-87) \%$ & $94(90-95) \%$ & 0.001 \\
\hline
\end{tabular}

Values are median (IQR).

$P$ values are derived by Kruscall-Wallis ANOVA, normal term infants and group I being different from group II.

(fig 1). There was, however, a persistent difference between the infants receiving $80 \%$ oxygen and the two other groups, the infants receiving $80 \%$ oxygen having a much higher $\mathrm{SaO}_{2}$ (table 1).

In the study group one infant was excluded after randomisation as he required intubation before 2 hours of age; all the remaining 69 infants were alive and breathing spontaneously, 65 of them on nasal CPAP, at 2 hours of life.

The perinatal characteristics were similar in the two groups and differed from the reference population only in terms of birthweight and temperature on admission to intensive care (table 2).

All infants were transported to intensive care within 10 minutes of delivery. This means that the duration of the planned different strategies for oxygen administration was less than 10 minutes. As transport time is on average 30

Table 2 Perinatal data for two randomisation groups and background population (values are median (range) or absolute numbers (\%))

\begin{tabular}{llcc}
\hline & $\begin{array}{l}\text { Group I } \\
(21 \% \text { oxygen }) \\
(n=34)\end{array}$ & $\begin{array}{l}\text { Group II } \\
(80 \% \text { oxygen }) \\
(n=36)\end{array}$ & $\begin{array}{l}\text { Background } \\
\text { population } \\
(n=115)\end{array}$ \\
\hline Birthweight (g) & $1043(610-2590)$ & $1113(550-1870)$ & $1320(700-2200)^{\star}$ \\
Gestational age (weeks) & $29(25-32)$ & $29(24-32)$ & $29(25-32)$ \\
Gender (M/F) & $24 / 10$ & $22 / 14$ & $63 / 51$ \\
Umbilical cord pH & $7 \cdot 32(7 \cdot 21-7 \cdot 44)$ & $7 \cdot 32(7 \cdot 02-7 \cdot 44)$ & $7 \cdot 33(6 \cdot 85-7 \cdot 51)$ \\
Apgar score 1 minute & $8(4-10)$ & $8(3-10)$ & $8(0-10)$ \\
Apgar score 5 minutes & $10(8-10)$ & $10(6-10)$ & $10(2-10)$ \\
Temperature ( ${ }^{\circ}$ C) & $37 \cdot 0(35 \cdot 0-38 \cdot 0)$ & $36 \cdot 9(35 \cdot 6-37 \cdot 5)$ & $36 \cdot 6(34 \cdot 7-37 \cdot 8)^{\star}$ \\
Caesarean section (No & $23(67 \cdot 6)$ & $29(80 \cdot 6)$ & $80(69 \cdot 6)$ \\
$\begin{array}{l}\text { Antenatal steroid }(\text { No }(\%)): \\
\text { None }\end{array}$ & $4(11 \cdot 8)$ & $2(5 \cdot 6)$ & $5(4 \cdot 3)$ \\
One dose & $6(17 \cdot 6)$ & $6(16 \cdot 7)$ & $18(15 \cdot 7)$ \\
Two doses & $24(70 \cdot 6)$ & $25(69 \cdot 4)$ & $84(79 \cdot 1)$ \\
No information & 0 & $3(8 \cdot 3)$ & $1(0 \cdot 9)$ \\
\hline
\end{tabular}

${ }^{\star} \mathrm{P}<0.01$, background population compared with study group; Mann-Whitney $\mathrm{U}$ test. seconds, neither CPAP, ventilation, nor oxygen were administered during the transport.

Fourteen infants received caffeine citrate and 54 received aminophylline shortly after birth. The infants were equally distributed between the two groups.

The infants in group I received less oxygen at the time of measurements than the infants in group II (median $\mathrm{FIO}_{2} 0.21 v 0.30, \mathrm{P}=0.004$, Mann-Whitney $U$ test), while no significant difference was found in $\mathrm{TcPO}_{2}$ between the groups.

Two hours after birth, CBF was significantly higher in group I than in group II (median (interquartile range): $15.9(13.6-21.9) \mathrm{ml}$ $100 \mathrm{~g} /$ minute $v \quad 12.3(10.7-13.8) \mathrm{ml} / 100$ $\mathrm{g} /$ minute; $\mathrm{P}<0.0001$, Mann-Whitney U test). LVO showed no significant difference between the groups (median (interquartile range): 235 (209-282) $\mathrm{ml} / \mathrm{kg} / \mathrm{minute} v 202$ (178-253) $\mathrm{ml} / \mathrm{kg} /$ minute; $\mathrm{P}=0 \cdot 10$, Mann-Whitney $\mathrm{U}$ test). Heart rate was significantly higher in group I than in group II whereas other parameters were similar (table 3 ). The distribution of CBF between the groups is shown in fig 2 .

Stepwise multiple regression analysis revealed that randomisation was the strongest explanatory variable on $\mathrm{CBF}$ at 2 hours of age $(P<0.0001) . \mathrm{TcPCO}_{2}(\beta=0.22, \mathrm{P}=0.04)$ and $\mathrm{TcPO}_{2}(\beta=0.23, \quad \mathrm{P}=0.04)$ were positively related to CBF; MABP, haemoglobin concentration, and gestational age did not reach significance. Neither LVO nor any other variable were significantly related to the different CBF values either in univariate analysis or in multiple regression analysis in combination with randomisation.

Nine $(26.5 \%)$ infants in group I required supplemental oxygen during the first 10 minutes of life, maximal $\mathrm{FIO}_{2}$ was 0.35 in four infants and 0.50 in five. Significantly more of these nine infants still required supplemental oxygen at the age of 2 hours compared with the rest of group I (6/9 v5/25, P=0.03, $\chi^{2}$ test). No differences in perinatal data, CBF (median (interquartile range) $\mathrm{CBF}$ : +extra $\mathrm{O}_{2} \quad 16 \cdot 2$ $(12 \cdot 6-24 \cdot 3) \mathrm{ml} / 100 \mathrm{~g} /$ minute $v$-extra $\mathrm{O}_{2} 15 \cdot 7$ (13.6-20.8) $\mathrm{ml} / 100 \mathrm{~g} /$ minute; $\mathrm{P}=0 \cdot 78$, MannWhitney U test), or other variables at 2 hours of age were found between these two subgroups of infants, which is why they were not separated in the analysis.

All those infants not receiving supplemental oxygen at 2 hours of age (group $I, n=23$, group II, $n=12$ ) had been without supplemental oxygen for at least 90 minutes before CBF was measured. Analysis of this subgroup revealed a significant difference in CBF between the randomisation groups (median (interquartile range): group I $16 \cdot 1$ $(13 \cdot 6-22 \cdot 6) \mathrm{ml} / 100 \mathrm{~g} /$ minute, group II $12 \cdot 6$ $(10 \cdot 1-14 \cdot 6) \mathrm{ml} / 100 \mathrm{~g} /$ minute; $\mathrm{P}=0.006$, Mann-Whitney U test).

Short term outcome (table 4) was similar between the two study groups and between the total study group and the reference population. Cystic periventricular leucomalacia was not diagnosed in any infant included in the study. 
Table 3 Median (interquartile range) data for two randomisation groups at time of measurement (= postnatal age)

\begin{tabular}{|c|c|c|c|}
\hline Variable & $\begin{array}{l}\text { Group I ( } 21 \% \text { oxygen }) \\
(n=34)\end{array}$ & $\begin{array}{l}\text { Group II ( } 80 \% \text { oxygen }) \\
(n=35)\end{array}$ & $\begin{array}{l}P \\
\text { value }\end{array}$ \\
\hline $\begin{array}{l}\mathrm{CBF}(\mathrm{ml} / 100 \mathrm{~g} / \text { minute) } \\
\mathrm{LVO}(\mathrm{ml} / \mathrm{kg} / \mathrm{minute}) \\
\mathrm{FIO}_{2} \\
\mathrm{TcPO}_{2}(\mathrm{kPa}) \\
\mathrm{PCO}_{2}(\mathrm{kPa}) \\
\mathrm{MABP}(\mathrm{mm} \mathrm{Hg}) \\
\mathrm{Heart} \text { rate }(\mathrm{bpm}) \\
\text { Haemoglobin (mmol/l) } \\
\text { Blood glucose (mmol/1) } \\
\text { Postnatal age (minutes) }\end{array}$ & $\begin{array}{c}15 \cdot 9(13 \cdot 6-21 \cdot 9) \\
235(209-282) \\
0 \cdot 21(0 \cdot 21-0 \cdot 30) \\
11 \cdot 0(9 \cdot 3-12 \cdot 5) \\
6 \cdot 0(5 \cdot 3-6 \cdot 7) \\
36 \cdot 5(33 \cdot 8-40 \cdot 0) \\
158(150-165) \\
11 \cdot 8(10 \cdot 7-12 \cdot 7) \\
3 \cdot 3(2 \cdot 2-4 \cdot 7) \\
133(120-150)\end{array}$ & $\begin{array}{c}12 \cdot 3(10 \cdot 7-13 \cdot 8) \\
202(178-253) \\
0 \cdot 30(0 \cdot 21-0 \cdot 38) \\
11 \cdot 8(10 \cdot 8-13 \cdot 1) \\
6 \cdot 1(5 \cdot 3-6 \cdot 9) \\
36 \cdot 0(32 \cdot 0-42 \cdot 0) \\
150(140-163) \\
12 \cdot 0(11 \cdot 0-12 \cdot 9) \\
3 \cdot 3(2 \cdot 2-3 \cdot 9) \\
145(130-150)\end{array}$ & $\begin{array}{l}<0.0001 \\
0 \cdot 10 \\
0.004 \\
0.10 \\
0.61 \\
0.74 \\
0.02 \\
0.77 \\
0.81 \\
0.11\end{array}$ \\
\hline
\end{tabular}

${ }^{\star}$ Mann-Whitney U test. were not collected at the time of CBF measurement. The reason for the high levels of $\mathrm{TcPO}_{2}$ in both groups may be that a probe temperature of $44^{\circ} \mathrm{C}$ for transcutaneous measurements produces an overreading of $\mathrm{PO}_{2}$ in patients with a thin epidermis when compared with arterial measurements. ${ }^{20}$ An overreading of more than $2 \mathrm{kPa}$, however, is unusual and few infants could have been significantly hypoxaemic - that is, $\mathrm{PaO} 2$ below $7 \mathrm{kPa}$ at the time of CBF measurement. Multiple linear regression showed that group assignment remained the strongest explanatory variable on $\mathrm{CBF}$, but, surprisingly, regression also showed that $\mathrm{CBF}$ was slightly positively associated with the current $\mathrm{TcPO}_{2}$ level. The correlation between $\mathrm{TcPO}_{2}$ and CBF may have been confounded by intermediate factors (indicating the possibility of bias in transcutaneous measurement of oxygen tension), or may simply be random. The need for more oxygen in group II could possibly be explained by toxic oxygen metabolites which are known to produce bronchoconstriction and pulmonary vasoconstriction. ${ }^{21}$ However, the pulmonary effects of oxygen exposure were not directly examined in this study.

In summary, although our data are imperfect, we found no other likely explanation for the difference in CBF at 2 hours of age than the difference in oxygen exposure preceding the measurement. This suggests a prolonged effect of hyperoxaemia, possibly mediated through toxic oxygen metabolites on cerebral vessels of the newborn premature infant. The effect seemed to be more pronounced for cerebral vessels than for systemic circulation, as cardiac left ventricular output was not significantly lower in the infants treated with $80 \%$ oxygen. The statistical power of the

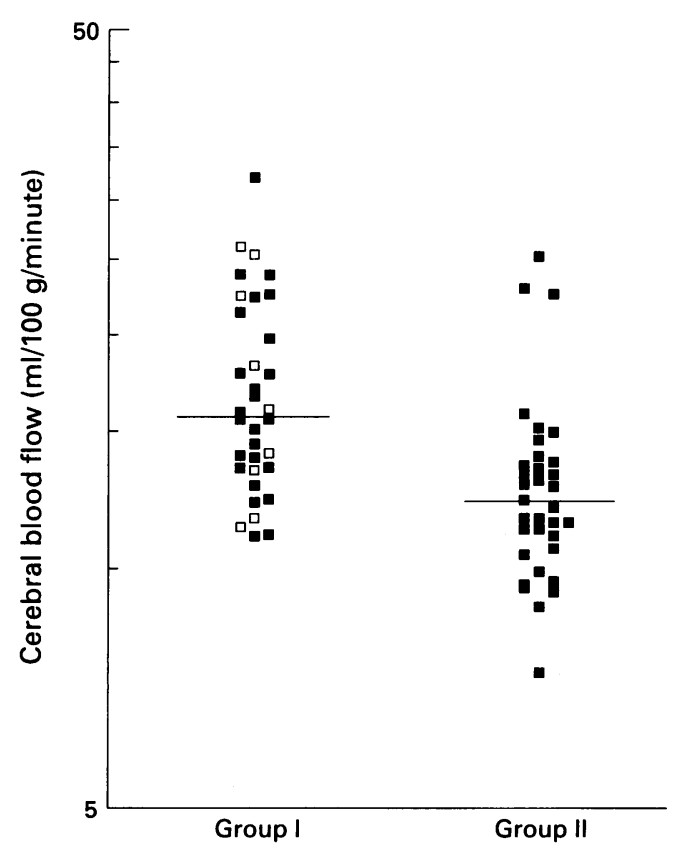

Figure 2 Distribution of $C B F$ values in infants randomised to receive $21 \%$ oxygen (group I) or $80 \%$ oxygen (group II) at birth. Infants in group I receiving supplemental oxygen at birth are indicated by $\square$. Median values are marked. Notice that the ordinate is logarithmic. birth but there was no difference in $\mathrm{TcPo}_{2}$ between the groups. Arterial blood samples 


\begin{tabular}{lllc}
\hline & $\begin{array}{l}\text { Group I } \\
(21 \% \text { oxygen }) \\
(n=34)\end{array}$ & $\begin{array}{l}\text { Group II } \\
(80 \% \text { oxygen }) \\
(n=35)\end{array}$ & $\begin{array}{l}\text { Background } \\
\text { population } \\
(n=115)\end{array}$ \\
\hline Dead & $2(5 \cdot 9)$ & $6(17 \cdot 1)$ & $7(6 \cdot 1)$ \\
Retinopathy of prematurity (grade 3-5) & $1(2 \cdot 9)$ & $2(5 \cdot 7)$ & $2(1 \cdot 7)$ \\
Necrotising enterocolitis & $2(5 \cdot 9)$ & $1(2 \cdot 9)$ & $3(2 \cdot 6)$ \\
Intraventricular haemorrhage (grades III-IV) & $2(5 \cdot 9)$ & $3(8 \cdot 6)$ & $9(7 \cdot 8)$ \\
Oxygen therapy day 28 & $5(14 \cdot 7)$ & $2(5 \cdot 7)$ & $9(7 \cdot 8)$ \\
Persistent ductus arteriosus & $4(11 \cdot 8)$ & $7(20 \cdot 0)$ & $17(14 \cdot 8)$ \\
RDS (surfactant treatment) & $3(8 \cdot 8)$ & $6(17 \cdot 1)$ & $16(13 \cdot 9)$
\end{tabular}

The figures are absolute numbers (\% of group).

No significant difference is present between the two randomisation groups or between the study group and the background population.

study, however, was not sufficient to rule out an effect on LVO. The small but significant difference in heart rate between the groups may be random, and no correlation was present between $\mathrm{CBF}$ and heart rate.

Stuart et $a^{22}$ demonstrated that short term (20 minutes) in vitro exposure of umbilical vessels to a $95 \%$ oxygen $-5 \%$ carbon dioxide gas mixture caused a $30 \%$ inhibition in the ability to produce prostacyclin, an important vasodilator and antithrombotic metabolite of arachidonic acid. In another study of 4 to 6 day old kittens a $33 \%$ reduction in retinal 6-ketoprostaglandin $\mathrm{F}_{1 \mathrm{a}}$ (the end product of prostacyclin) was observed after 48 hours of treatment with $80 \%$ oxygen, and these changes were still present after 24 hours of recovery in room air. ${ }^{23} \mathrm{~A}$ reduction in total retinal prostanoids which paralleled the changes observed in prostacyclin was also found, suggesting that the biochemical effect of hyperoxia on retinal vascular arachidonic acid metabolism occurred at the level of cyclooxygenase. Hyperoxia could exert a similar effect on the prostacyclin production of endothelial cells of cerebral vessels of preterm infants. Continued presence of cyclooxygenase inhibitors like free oxygen radicals following the hyperoxaemic insult or a slow turnover rate of cyclo-oxygenase in preterm cerebral endothelium might explain the prolonged effect.

Adenosine is believed to have an important role in the regulation of cerebrovascular resistance. ${ }^{24}$ However, 68 of the infants included in this study received either aminophylline or caffeine citrate. Both drugs are antagonists to adenosine $^{25}$ and an effect of hyperoxaemia mediated through adenosine receptors therefore seems unlikely.

Prolonged cerebral vasoconstriction may make the brain more susceptible to hypoxaemic episodes or ischaemia. Hypoxaemia or normoxaemia in the recovery period from oxygen induced retinopathy worsened the pathological findings in kittens while treatment with $28 \%$ oxygen in the same period ameliorated the retinopathy compared with recovery in room air. ${ }^{26} 27$ In contrast, hyperoxaemia did not influence the brain damage in newborn piglets resuscitated from profound hypoxia with either $21 \%$ or $100 \%$ oxygen. ${ }^{28}$ Our data show that most preterm infants $(25 / 34$, or $74 \%$ ) can be stabilised at birth without supplemental oxygen. The results are in agreement with a study of asphyxiated, mainly term, newborn infants in India randomised to receive $100 \%$ oxygen or room air during the resuscitation. ${ }^{29}$ Obviously, most of our infants were in a good condition as judged by umbilical cord $\mathrm{pH}$ and Apgar scores. No infant in our study required intubation in the delivery room and only nine infants developed respiratory distress requiring surfactant replacement therapy (indication for surfactant was a: $\mathrm{A}-\mathrm{PO}_{2}$ of $<0.22$ and radiological respiratory distress syndrome). This may be due to the good overall social conditions in Denmark, including effective antenatal care with extensive use of steroids and proactive management of delivery. Thus the success of atmospheric air in our study may not be reproducible in other populations of preterm infants.

In conclusion, our study suggests that routine administration of high oxygen concentration just after birth produces á persistent cerebral vasoconstriction in premature neonates while supplemental oxygen administered on clinical indication did not influence CBF. This may be specific for preterm neonates in the period immediately after birth. The potential biological and clinical implications are important. The prevention and treatment of hypoxia must remain the highest priority during resuscitation. However, a vasoconstriction and in particular a reduced vasodilating capacity of the cerebral vessels may increase the risk of cerebral damage in the newborn period. Our results need to be confirmed in a different clinical setting.

1 Leahy FAN, Cates D, MacCallum M, Rigatto H. Effects of $\mathrm{CO}_{2}$ and $100 \% \mathrm{O}_{2}$ on cerebral blood flow in preterm infants. F Appl Physiol 1980; 48: 468-72.

2 Rahilly PM. Effects of $2 \%$ carbondioxide, $0.5 \%$ carbondioxide and $100 \%$ oxygen on cranial blood flow of the human neonate. Pediatrics 1980; 66: 685-9.

3 Kennedy C, Grave GD, Jehle JW. Effect of hyperoxia on the cerebral circulation of the newborn puppy. Pediatr Res 1971; 5: 659-67.

4 Ashton N, Cook C. Direct observation of the effect of oxygen on developing vessels. $\mathrm{Br} ¥ \mathrm{O}$ Ophthalmol $1954 ; 38$ : 433-40.

5 Nijima S, Shortland DB, Levene MI, Evans DH. Transient hyperoxia and cerebral blood flow velocity in infants born prematurely and at full term. Arch Dis Child 1988; 63 1126-30.

6 Svenningsen NW, Stjernquist K, Stavenov S, HellstromVestas L. Neonatal outcome of extremely low birthweigh liveborn infants below $901 \mathrm{~g}$ in a Swedish population. Acta Paediatrica Scandinavia 1989; 78: 180-8.

7 Roberton NRC. Resuscitation of the Newborn. In: Roberton NRC, ed. Textbook of neonatology. Edinburgh: Churchill Livingstone, 1992: 173-95.

8 Greisen $\mathrm{G}$. Cerebral blood flow in preterm infants during the first week of life. Acta Paediatrica Scandinavia 1986; 75: 43-51.

9 Pryds O, Andersen GE, Friis-Hansen B. Cerebral blood flow reactivity in spontaneously breathing, preterm infants shortly after birth Acta Paediatrica Scandinavia 1990; 79, 391-6.

10 Altmann DI, Powers WJ, Perlmann JM, Herscovitch $P$, Volpe SL, Volpe JJ. Cerebral blood flow requirement for brain viability in newborn infants is lower than in adults. Ann Neurol 1988; 24: 218-26.

11 Lundstrøm KE, Greisen G. Early treatment with nasalCPAP. Acta Paediatrica Scandinavia 1993; 82: 856.

12 Greisen G, Pryds O. Intravenous ${ }^{133} \mathrm{Xe}$ clearance in preterm neanates with respiratory distress. Internal validation of $\mathrm{CBF}$ as a measure of global cerebral blood flow. Scand $f$ Clin Lab Invest 1988; 48: 673-8.

13 Obrist W, Thompson HK, Wang HS, Wilkinson WE. Regional cerebral blood flow estimated by ${ }^{133} \mathrm{Xe}$ inhalation. Stroke 1975; 6: 245-56.

14 Greisen G, Trojaborg W. Cerebral blood flow, $\mathrm{PaCO}_{2}$ changes and visual evoked potentials in mechanically venchanges and visual evoked potentials in mechanically ven76: 394-400.

15 Mellander M, Sabel K, Caidahl K, Solymar L, Eriksson B Doppler determination of cardiac output in infants and children: comparison with simultaneous thermodilution Pediatr Cardiol 1987; 8: 241-6.

16 Alverson DC. Pulsed Doppler assessment of ascending aorta flow velocity in newborns and infants: clinical 
applications. Echocardiography, A Review of Cardiovascular Utrasound 1988; 5: 1-22.

17 Harris AP, Sendak MJ, Donham RT. Changes in arterial oxygen saturation immediately after birth in the human neonate. $\mathcal{F}$ Pediatr 1986; 109: 117-9.

18 House JT, Schultetus RR, Gravenstein N. Continuous neonatal evaluation in the delivery room by pulse oximetry. $\mathcal{f}$ Clin Monitor 1987; 3: 96-100.

19 Deckardt R, Schneider KTM, Graeff H. Monitoring arterial oxygen saturation in the neonate. $\mathcal{F}$ Perinat Med 1987; 15: $357-60$.

20 Friis-Hansen B, Voldsgaard P, Witt J, Pedersen KG, Frederiksen PS. The measurement of $\mathrm{TcPO}_{2}$ and $\mathrm{TcPCO}_{2}$ in newborn infants at $44^{\circ} \mathrm{C}, 42^{\circ} \mathrm{C}$ and $37^{\circ} \mathrm{C}$ after initial heating to $44^{\circ} \mathrm{C}$. In: Huch A, Huch R, Rooth G, eds. Advances in Experimental Medicine and Biology, Vol 220: Continuous Transcutaneous Monitoring. New York: Plenum Press, 1987: 35-40.

21 Kjæve J, Vaage J, Bjertnæs L. Toxic oxygen metabolites induce vasoconstriction and bronchoconstriction in isolated, plasma-perfused rat lungs. Acta Anaesthesiol Scand 1991; 35: 65-70.

22 Stuart MJ, Setty BMJ, Walenga RW, et al. Effects of hyperoxia and hypoxia on vascular prostacyclin formation in vitro. Pediatrics 1984; 74: 548-53.
23 Stuart MJ, Phelps DL, Setty BMY. Changes in oxygen tension and effects of cyclooxygenase metabolites: III. Decrease of retinal prostacyclin in kittens exposed to hyperoxia. Pediatrics 1988; 82: 367-72.

24 Phillis JW. Adenosine in the control of the cerebral circulation. Cerebrovasc Brain Metab Rev 1989; 1: 26-54.

25 Rall TW. Drugs used in the treatment of asthma. In: Goodman Gillman A, Rall TW, Nies AS, Taylor P, eds. The Pharmacological Basis of Therapeutics. New York: The Pharmacological Basis of

26 Phelbs DL, Rosenbaum AL. Effects of marginal hypoxemia on recovery from oxygen-induced retinopathy in the kitten model. Pediatrics 1984; 73: 1-6.

27 Phelbs DL. Reduced severity of oxygen-induced rethinopathy in kittens recovered in $28 \%$ oxygen. Pediatr Res 1988; 24: 106-9.

28 Rootvelt T, Loberg EM, Moen A, Øyasæter S, Saurstad OD. Hypoxemia and resuscitation with $21 \%$ or $100 \%$ oxygen in newborn pigs: changes in blood pressure, base deficit, and hypoxanthine and brain morphology. Pediatr Res 1992; 32: 107-13.

29 Ramji S, Rooth G, Saugstad OD. Resuscitation of asphyxic newborn infants with room air or $100 \%$ oxygen. Pediatr Res 1993; 34: 809-12. 